\title{
PASSOS, João Décio; USARSKI, Frank. (Org.). Compêndio de Ciência da Religião. São Paulo: Paulinas: Paulus, 2013. 703p. ISBN: 978-85-356-3576-8.
}

Jaqueline Crepaldi Souza*

Acabou-se a batalha a respeito dos termos. A preocupação com os nomes "Ciência" ou "Ciências" da Religião importa, mas passa a ser vista como candidata a conceitos nesta obra. Os temas abordados pelo Compêndio vão além. Escrito por muitas mãos, ele representa os Cientistas da Religião.

João Décio Passos e Frank Usarski são os autores e organizadores dessa obra. Passos é Doutor em Ciências Sociais, teólogo e professor de Ciência da Religião na Pontifícia Universidade Católica de São Paulo. Usarski é Doutor em Ciência da Religião pela Universidade de Hannover, Livre-Docente em Ciência da Religião pela Pontifícia Universidade Católica de São Paulo e Professor assistente do Departamento de Ciência da Religião na mesma Universidade. Eles fazem esta parceria com vários outros pesquisadores doutores.

$\mathrm{Na}$ introdução, Passos e Usarski apresentam o objetivo de buscar legitimidade disciplinar para uma Ciência da Religião. Eles se baseiam em duas

\footnotetext{
Resenha recebida em 14 de maio de 2014 e aprovada em 11de junho de 2014.

* Mestranda em Ciências da Religião no Programa de Pós-graduação em Ciências da Religião da PUC Minas. . País de origen: Brasil. E-mail: jacquelinecrepaldi@yahoo.com.br.
} 
colunas, isto é, um pilar histórico e um pilar sistemático. Fatos e conceitos ajudam a aprofundar os desafios de aspectos hermenêuticos, epistemológicos, metodológicos e éticos em Ciência da Religião. Além dessas discussões, os autores analisam os obstáculos epistemológicos e políticos institucionalizados nos aspectos cultural, religioso e político no Brasil. Suas abordagens permitem expor objetos, métodos e teorias para essa ciência. Articulando várias disciplinas, perfazem o trajeto de nascimento e desenvolvimento da Ciência da Religião. Apresentam a fundamentação epistemológica da Ciência da Religião, passam pelas abordagens da linguagem e abordagem social, culminando com a Ciência da Religião aplicada.

Na primeira parte, a epistemologia da Ciência da Religião é apresentada por Eduardo Rodrigues Cruz com noções, conceitos e categorias presentes na academia, além de uma análise da proposta de Mircea Eliade, e as respostas que seus críticos forneceram nas últimas décadas. Interessante leitura são as abordagens evolutivas de cunho darwiniano, que procuram identificar manifestações do que entendemos como religião, no passado evolutivo humano. A seguir, é apresentada a história da ciência da religião por Frank Usarski. Buscando um status quo "ideal" da disciplina como referencial, ele fala da tendência constitutiva para a formação da Ciência da Religião e de sua fase formativa. Steven Engler e Michael Stausberg fazem um esboço da pesquisa, métodos qualitativos e quantitativos, critérios de excelência, dados, teorias e métodos. A fenomenologia da religião é apresentada a seguir por Nicola Maria Gasbarro. A partir do relacionamento crítico entre Rudolf Otto e Gerard van der Leeuw, são apresentados os pontos de maior incidência das estruturas epistemológicas consolidadas que determinam a generalização teórica e metodológica da Fenomenologia da Religião, suas venturas e desventuras. A Filosofia da Religião é contemplada por Scott Randall Paine com conceitos, antecedentes da Filosofia da Religião que levam a um esboço do perfil atual que está, ainda em muitos aspectos, em evolução de autoentendimento e método. As Ciências Naturais, a Religião e a Teologia são temas estudados por Eduardo Rodrigues Cruz. Entre eles, o conflito entre ciência e religião. Além de estudar Religião e Teologia na modernidade, aborda na Ciência, a 
"tradição recebida” e a secularização. Instigante é o tema NOMA (iniciais para Non-interfering magisteria, “magistérios não interferentes”). O NOMA é proposta de um famoso biólogo e divulgador da ciência, Stephen J. Gould. Para ele, ciência e religião representam dois magistérios, que falam de coisas diferentes e não têm por que competir. A seguir, Religião e epistemologias pós-coloniais são apresentadas por Lauri Emílio Wirth. Em sua crítica ao projeto inicial de uma Ciência da Religião, o autor parte de contextos de dominação que acompanham os projetos de colonização das mesmas nações que produzem o saber científico. O autor dá voz ao "subalterno".

Outra proposta interessante é a noção de hermenêuticas diatópicas. Nelas, o diálogo e o confronto com outras culturas e religiões podem ser enriquecidos. A religião como forma de conhecimento é o assunto tratado por Roberto Hofmeister. $\mathrm{Na}$ nossa avaliação, o conhecimento religioso que ficou centrado, apenas, no Cristianismo, poderia ter sido ampliado. Luiz Felipe Pondé apresenta questões importantes como: “Que tipo de pessoa nós queremos ser”? “Que tipo de sociedade queremos ter"? O impacto da moral contemporânea sobre a religião é o foco do texto. Nele, o autor faz uma reflexão a respeito da necessidade de romper com o entrincheiramento da Teologia para o bem comum da comunidade humana.

A segunda parte do Compêndio é apresentada por Maria José Rosado. Nela, as Ciências Sociais da Religião estimulam quem se interessa pelo universo das crenças religiosas. A discussão da Ciência da Religião como vocação, de Breno Martins Campos, mostra-se muito instigante. Estabelece contraponto às formulações de Weber no ensaio “A ciência como vocação”. Outra discussão importante está no texto História das Ciências Sociais da Religião, de Maria das Dores Campos Machado. Ela apresenta o desafio de interpretar o fenômeno religioso e suas consequências para a vida social. Já no texto de Fernando TorresLondoño há uma tentativa de esboçar um panorama da História das religiões. Sua avaliação histórica, sem pretensão de submissão a uma escola específica ajuda a entender uma disciplina em formação. Sentimos falta, aí, de uma conceituação 
mínima de etnologia, uma vez que a categoria atravessa várias vezes o texto. A seguir, Ricardo Mariano apresenta a Sociologia da Religião e seu foco na secularização. Silas Guerriero fala sobre a Antropologia da Religião. Ele nos remete aos aspectos simbólicos que envolvem a construção do fato religioso no interior das sociedades humanas. Impactante é a visão do "ponto de vista do nativo". Nele, o universo simbólico é visto como elemento fundamental das comunicações e das trocas. Assim, o simbolismo da experiência corporal se faz descobrir. Além do rito, interessa ao autor a estrutura básica dos mitos, primordial ao pensamento humano. A seguir, Jens Schlamelcher faz uma abordagem econômica da Religião. Destacamos a clareza com que explica os conceitos religiosos como habitus, campo e capital, em Pierre Bourdieu. Em seguida, Sylvio Fausto Gil Filho foca a Geografia da Religião. De particular interesse é o quadro de formação histórica de relação religião/ambiente apresentado pelo autor, além da explicação a respeito da "virada cultural" na geografia analisando o espaço sagrado como forma projetada pelo sujeito. Marcelo Ayres Camurça apresenta a religião como organização. Ele examina aspectos formais, estruturais e materiais da instituição religiosa: agentes, regras, rituais doutrinas, etc. Com clareza, o autor expõe o trabalho de Joachim Wach sobre as formas de expressão da experiência religiosa. Texto denso que contrapõe teorias e tipologias como carisma versus instituição, igreja versus seita, e outras. Para finalizar a parte dois, Cecília Loreto Mariz contribui com o tema Instituições tradicionais e movimentos emergentes, com o foco empírico no cristianismo ocidental e o foco teórico Weberiano. Destaca-se a explicação a respeito do carisma que perpassa todo o texto.

A terceira parte trata das Ciências Psicológicas da Religião. Edênio Valle faz a introdução afirmando que a coletânea de verbetes constitui um arsenal de sólidas referências sobre o que e como as ciências da psique estão se desenvolvendo em ambientes ligados à academia. Jacob Belzen explica a constituição histórica da Psicologia científica da religião. Ele apresenta a visão de alguns teólogos renomados que dizem que a Psicologia da Religião é um curto-circuito teológico. A seguir, Cátia Cilene Lima Rodrigues e Antônio Máspoli de A. Gomes mostram que a 
Psicologia da Religião tem por objetivo observar, descrever, compreender, controlar e, se possível, predizer o comportamento religioso humano por meio de métodos desenvolvidos pelas diferentes abordagens da Psicologia enquanto ciência. Sua discussão gira em torno de conceitos da Psicologia, bem como de importantes teóricos das áreas comportamental, psicodinâmica, humanista e cognitivista. Geraldo José de Paiva apresenta teorias contemporâneas da Psicologia da Religião. Interessante na Teoria Cultural é a diferenciação do êmico (o que é específico de uma cultura) e o ético (o que é equivalente em várias culturas). O autor José Luiz Cazarotto faz uma análise de interfaces entre Ciências Biológicas, Neurociências e religião. No debate sobre o cérebro religioso, o autor relata que as modernas tecnologias tendem a ajudar a perceber o que acontece no cérebro das pessoas que meditam ou estão em oração. Eliana Massih estuda a Psicologia evolucionária e religião. É uma tentativa de se desvendar o que e como os hominídeos se tornaram o que são hoje: seres da razão e do espírito. Pergunta instigante é a respeito do que a Psicologia evolucionária da Religião agrega ao conhecimento psicológico do comportamento religioso. Clarissa De Franco aborda a questão da Psicologia e espiritualidade, discutindo sob o viés da psicologia categorias como espiritualidade, religiosidade e religião. Desvendando esse "homem de espírito científico", a autora o situa num processo de secularização. Ela escolhe três elementos para nortearem seus trabalhos: prática da psicoterapia clínica, moralidade e morte. E conclui dizendo que a busca de sentido está na base da relação de autonomia para realização de potenciais humanos. Maria Eliane Azevedo da Silva introduz o tema da Psicologia do desenvolvimento e religião. Propõe uma pergunta fundante: o que se entende hoje, na Psicologia da religião, por amadurecimento da fé? A "busca de sentido" é retomada em estudos dos estágios da fé de Fowler, da "coragem da fé" de Tillich, da "casa de Deus" de Winnicott. Autores como Erikson, Piaget, Stern e Rizzuto são significativos para esses estudos. Eles ajudam a entender que amar e ser amado, ou o contrário, pode ser definidor da identificação de Deus pela criança. Welligton Zangari, Everton de Oliveira Maraldi, Leonardo Breno Martins e Fátima Regina Machado estudam os estados alterados de consciência (EACs) em relação à 
religião. Os autores explicam que esses estados são provocados pelo consumo de substâncias psicoativas, estados fronteiriços entre o sono e a vigília, estados de concentração profunda, entre outros.

Ênio José da Costa Brito faz a introdução da parte IV, o estudo das Ciências das Linguagens religiosas em que Paulo Augusto de Souza Nogueira, afirmando os limites e representações da linguagem religiosa, pergunta que tipo de relação existe entre a religião e a linguagem. Mais: pergunta se existiria religião sem linguagem. A perspectiva de linguagem como representação simbólica é vista como motor das transformações na estrutura cerebral humana. Etienne Alfred Higuet discute a hermenêutica da religião. Símbolos e mitos são mostrados na perspectiva da fenomenologia hermenêutica. O autor apresenta a hermenêutica como uma perspectiva que compreende a religião a partir de dentro, constituindo-se como pressuposto dos métodos, que, como a Semiótica, interpretam os textos a partir de sua estrutura linguística. Nesse complemento crítico se privilegiam abordagens empíricas e quantitativas. Pedro Lima Vasconcellos verifica o lugar dos estudos dos textos religiosos, especialmente as "escrituras”. Ele dá atenção especial à Tanak judaica e à Bíblia cristã, além de abordar o Corão muçulmano e outras escrituras. Um dos limites do texto refere-se ao universo da forma escrita. Ênio José da Costa Brito contribui com as tradições religiosas entre a oralidade e o conhecimento do letramento. José J. Queiroz trata do relevante tema "Mito". Nele, tenta definir mito, relatar sua história e apresentar posições relativas ao mito nos séculos XX e XXI. O autor fala do mito como uma realidade cultural complexa que pode ser abordada e interpretada de muitas perspectivas. A comunicação entre os mitos convida a pensar numa intercosmovisão, conceito explicitado no texto. Maria Angela Vilhena fala dos ritos religiosos e extrarreligiosos. Curiosa é a citação a respeito de velários virtuais nos sites e redes virtuais. Maria Antonieta Antonecci apresenta as expressões corporais e religião. Nelas, a formação da identidade afrobrasileira vai se formando. A religiosidade é vivida em performances carregadas de perspectivas ética e estética do grupo cultural. Brenda Carranza analisa a linguagem midiática e a religião. Faz uma leitura da disputa interna que setores 
católicos e alguns grupos evangélicos vêm travando na arena midiática há algumas décadas. César Augusto Sartorelli faz uma leitura das artes religiosas.

Afonso Maria Ligorio Soares faz a introdução à parte $\mathrm{V}$ que apresenta a aplicação da Ciência da Religião. Udo Tworuschka faz considerações teóricas e metodológicas a respeito da Ciência prática da Religião. Enzo Pace estuda a Ciência da Religião aplicada às relações internacionais. Sérgio Rogério Azevedo Junqueira apresenta a Ciência da Religião como a área que constituirá os fundamentos para o ensino religioso orientar seu conteúdo e sua forma no processo da educação. Edin Sued Abumanssur faz um estudo da Ciência da Religião aplicada ao turismo. Para ele, racionalidade e secularização da vida criam a modernidade. $\mathrm{O}$ turismo religioso está inserido aí. Mauro Passos estuda a Ciência da Religião aplicada à educação sócio-política e Paulo Mendes Pinto apresenta a Ciência da Religião aplicada ao patrimônio cultural. Afonso Maria Ligorio Soares estuda a Ciência da Religião aplicada à Teologia. Agenor Brighenti analisa a Ciência da Religião aplicada à pastoral. Práxis e reflexão constituem a ação. Ênio Brito Pinto busca esclarecer porque psicoterapeutas estudariam Ciência da Religião. Interessante explicação foi feita a respeito da consciência, ponto de convergência das operações humanas, que permite dizer o que estamos dizendo ou fazer o que fazemos como seres humanos. Ao tratar a religiosidade e a psicoterapia, o autor quer compreender o sujeito para ajudá-lo em seu processo de humanização.

Encontramos nos textos do Compêndio uma indicação, várias vezes repetida, que poderia ser traduzida por esta frase: "sobre isso, há ainda muito a pesquisar"; ou "sobre isso, há ainda alguma conceituação a ser melhor definida". Ainda assim, faz-se notório e relevante o empenho dos autores em apresentar um "produto" acadêmico de inegável valor e interesse. São várias disciplinas em torno do tema Religião. A linguagem é clara e precisa. As referências são atuais, enriquecedoras e necessárias ao debate sobre temas desta área de conhecimento. A obra revela um trabalho científico coletivo, apresenta conquistas inéditas e aperfeiçoamento de conhecimento na Ciência da Religião. Os autores começam 
expondo a parte histórica da disciplina, como foi fundada, principais autores e questões. Relacionam esses estudos com a Religião.

Comparam esse aparato com a modernidade e o contextualizam na contemporaneidade. Depois, analisando a disciplina no Brasil, concluem com sua projeção para o futuro. O termo cultura abrange amplamente os estudos do Compêndio, perpassando os textos de forma prática e atual. O Compêndio é uma obra que ajuda o leitor a identificar problemas empíricos e conceitos teóricos. Urge a continuação de trabalhos nesses moldes. A obra desperta no leitor o desejo de enveredar-se e aprofundar-se nos temas com outras leituras. 